\title{
AN ENHANCED MPPT TECHNIQUE FOR SMALL-SCALE WIND ENERGY CONVERSION SYSTEMS
}

\author{
Monica.S ${ }^{1}$, Ramesh $\mathbf{K}^{2}$ \\ ${ }^{\text {I}}$ P.G. Student, Department of Electrical and Electronics Engineering, Vivekanandha Collage of Engineering for \\ Women, Thiruchengode, Tamil Nadu, India \\ ${ }^{2}$ Assistant Professor, Department of Electrical and Electronics Engineering, Vivekanandha Collage of Engineering \\ for Women, Thiruchengode, Tamil Nadu, India
}

\begin{abstract}
This paper proposes an enhanced Maximum Power Point Technique (MPPT) based on Artificial Neural Network (ANN) for small-scale wind energy conversion systems using Permanent Magnet synchronous Generators (PMSGs). The conventional MPPT technique which used a Perturb and observes (P\&O) method is compared with the proposed ANN method. For this, MATLAB/Simulink is used to simulate both the conventional P\&O method and the proposed ANN method. The proposed ANN uses the dc-link voltage and duty cycle as the control variables for MPPT. The advantages of the proposed MPPT are low system cost, increase reliability, less mechanical stress of the generator and no need for shaft speed sensing. Moreover the conversion efficiency of the proposed ANN method is increased while comparing with the conventional P\&O method.
\end{abstract}

Keywords: Maximum Power Point Technique (MPPT), Perturb and Observe Algorithm (P\&O), Artificial Neural Network (ANN), Wind Energy Conversion System (WECS).

\section{INTRODUCTION}

In recent years, the demand for renewable energy has been increased since the prices of conventional fuels are increased. There are different kinds of renewable energy sources available. Wind, solar, biomass renewable resources are clean whereas it reduces green house gases. Among all other sources wind energy get more attention since the easy access and fast implementation of WECS. In case of wind energy source, a wind turbine and a power conversion system are used to produce the electrical energy. For this, a number of Wind Energy Conversion Systems (WECS) are implemented as research projects. Especially in remote areas where grid access is not possible, small-scale WECS are used for residential applications. To design such type of WECS, permanent-magnet synchronous generators are used since the advantages of their compact size, high efficiency, high power density, low maintenance cost and easy control.

To extract the optimum power point in the WECS, a maximum power point tracking (MPPT) algorithm has to be implemented. The accuracy of peak power points tracked by MPPT algorithm is responsible for the amount of power output from a WECS. The maximum power extraction algorithms can be classified into three main control methods, namely Tip Speed Ratio (TSR) control, Perturb and Observe (P\&O) control, and Optimum-Relation-Based (ORB) control.

TSR control method is simple. But it needs the accuracy of the wind speed measurement, which is a difficult process for such methods. The TSR control method regulates the rotational speed of the generator in order to maintain the
TSR to an optimum value at which power extracted is maximum. In this method, optimal TSR is maintained using measured wind speed and turbine shaft speed [4] and [6].

In ORB control, the MPP is tracked with the aid of optimum relation between different system variables. Many researchers use the power versus the shaft speed and the power versus the torque as the curve for MPP tracking. The power versus the shaft speed is used [9], [11] and [12]. The power versus the torque is used [7] and [13]. The use of the power versus the rectified dc-link voltage curve for MPP tracking is proposed in [14] and [15]. ORB algorithms have good dynamic response and simple implementation. Though ORB control is mostly used for WECS, it needs the prior knowledge of accurate system parameters that varies from one system to another and also may change due to system aging. This is the main drawback of this method. Therefore such methods requires continuous simulations and lab testing to acquire the prior knowledge of the system parameters.

The $\mathrm{P} \& \mathrm{O}$ control algorithms use the optimum relationship of the system to track the MPP by continuously changing the maximizing variable and observing the power captured. Based on the power measurements variation with the perturbation introduced, the next perturbation size and direction may be determined until the algorithm reaches the MPP. Most of the work done for MPPT using P\&O has used the power-speed relation of the wind turbine [1]. But there is a possibility of using other system parameters as control variables for the MPPT, like the dc-link voltage and the duty cycle [5] which in turn will reduce the cost of system and increase reliability by removing the need for shaft speed 
sensing. Wind speed measurements are not needed for $\mathrm{P} \& \mathrm{O}$ algorithms. This reduces the cost even further. Prior knowledge of the system parameters is not needed for the algorithm to work, making this method more reliable and less complex.

Performance enhancement and efficiency optimization are focused in [17], [18] using fuzzy logic control which is used to achieve faster convergence and accept inaccurate signals. In [2], the proposed method used the Jordan type recurrent Neural Network (NN) trained online using backpropagation. This method generate the output optimum speed without needing the knowledge of wind speed and other turbine parameters. Using ANN controller, minimum error MPPT is proposed in [3] without any complicated mathematical manipulations.

The main objective of this paper is to propose an enhanced $\mathrm{P} \& \mathrm{O}$ based MPPT technique using $\mathrm{ANN}$, in order to increase the tracking response and tracking efficiency. The proposed ANN has the dc-link voltage and duty cycle as the control inputs for the MPPT.

\section{CONFIGURATION OF WECS}

The block diagram of the WECS to which the MPPT algorithm will be applied is shown in Figure 1. The wind turbine is directly coupled to the PMSG. Compared to other generators, the PMSG has the advantage of being directly coupled to a wind turbine with no need for a gear box; there is no need for excitation current as in the doubly fed induction generator (DFIG) case, and there is no direct connection between the generator and the grid for grid tie applications. The schematic designed for the WECS is as shown in Figure 2. The load $R_{o}$ can be replaced by a unity power factor inverter that supplies a standalone ac load or is connected to the utility grid. In this thesis, a resistor is used as the load, and the MPP will be reflected into maximum voltage across it.

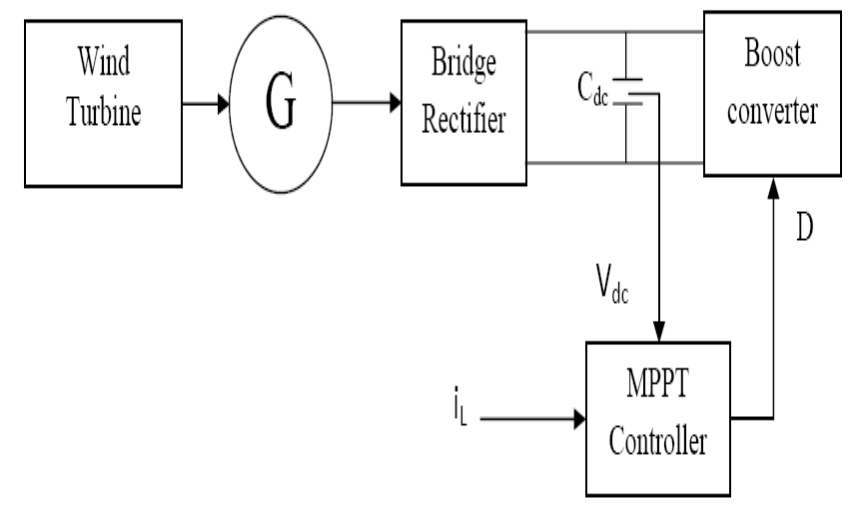

Fig 1 Block diagram of WECS

The diode bridge rectifier is used rather than a three-phase controlled PWM rectifier because of its lower cost and higher reliability. The boost converter consisting of the inductor $L$, the diode $D$, and the switch $Q$ will be current controlled to track the MPP and boost the voltage across the load resistor. The generator parameters used for this simulation are listed in Table.1.

Table.1: Parameters Of Generator And Boost Converter

\begin{tabular}{|l|l|l|l|}
\hline Generator & Value(Unit) & $\begin{array}{l}\text { Boost } \\
\text { Converter }\end{array}$ & Volme(Init) \\
\hline Power rating & $1(\mathrm{~kW})$ & $\mathrm{L}$ & $12(\mathrm{uF})$ \\
Pole pairs & 4 & $\mathrm{C}_{\mathrm{dc}}$ & $1(\mathrm{mF})$ \\
Rated Torque & $60(\mathrm{Nm})$ & $\mathrm{Co}$ & $0.1(\mathrm{~F})$ \\
Base Speed & $1500(\mathrm{rpm})$ & $\mathrm{RL}$ & $100(\Omega)$ \\
$\mathrm{Rs}$ & $0.18(\Omega)$ & & \\
$\mathrm{Ld}$ & $8.5(\mathrm{mH})$ & & \\
$\mathrm{La}$ & $8.5(\mathrm{mH})$ & & \\
$\mathrm{J}$ & 0.00062 & & \\
\hline
\end{tabular}

\subsection{Characteristics of WECS}

The mechanical power of the wind $P_{\text {wind }}$ can be expressed as

$$
P_{\text {wind }}=\frac{1}{2} \rho \pi R^{2} V^{3}
$$

Where $\rho$ is the air density, $R$ is the turbine radius, and $V$ is the wind speed.

The power captured by the blades of the turbine $P_{\text {blade }}$ is

$$
P_{\text {blade }}=\frac{1}{2} \rho \pi R^{2} V^{3} C_{P}(\lambda)
$$

Where $C_{P}(\lambda)$ is the turbine power coefficient.

The nonlinear function of the TSR $\lambda$ and the pitch angle $\beta$ can be expressed as follows

$$
\begin{gathered}
C_{P}(\lambda, \beta)=0.5176\left(116 \frac{1}{\lambda_{i}}-0.4 \beta-\right. \\
5-21(1 \lambda i)+0.0068 \lambda \\
\frac{1}{\lambda_{i}}=\frac{1}{\lambda+0.08 \beta}-\frac{0.035}{\beta^{3}+1} \\
\lambda=\Omega R / V
\end{gathered}
$$

Where $\Omega$ is the generator rotor speed of rotation (rpm)

Typical $C_{P}(\lambda)$ curve is shown in Fig. 3.

Considering the generator efficiency $\eta_{G}$, the total power produced by the generator $P$ is

$$
P=\eta_{\mathrm{G}} \mathrm{P}_{\mathrm{G}}
$$

The generator power coefficient is maximized for a tipspeed ratio value $\lambda_{\text {opt }}$ when the blades pitch angle is $\beta$ $=0$. The generator power curves for various wind speeds are 
shown in Fig. 4. It is observed that, for each wind speed, there exists a specific point in the generator output power versus rotating-speed characteristic where the output power is maximized. The control of the generator load results in a variable-speed generator operation, such that maximum power is extracted continuously from the wind (MPPT control). The value of the tip-speed ratio is constant for all maximum power points (MPPs), while the generator speed of rotation is related to the wind speed as follows:

$$
\Omega_{\mathrm{n}}=\lambda_{o p t} \frac{V_{n}}{R}
$$

Where $\Omega_{\mathrm{n}}$ is the optimal generator speed of rotation at a wind velocity $V_{n}$.

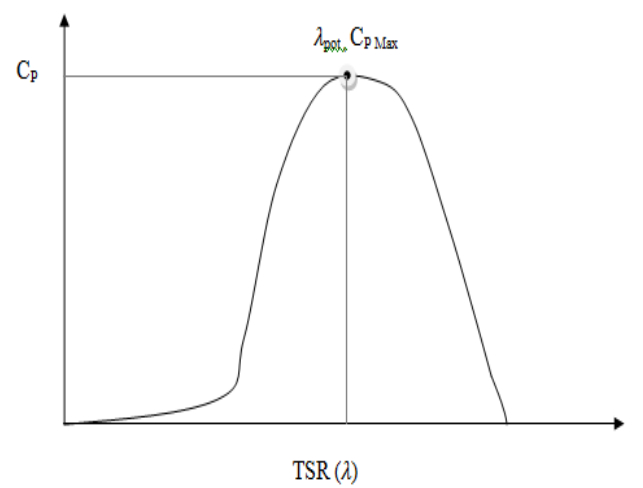

Fig. 3 Typical power coefficient as function of the TSR curve

Besides the optimal energy production capability, another advantage of variable-speed operation is the reduction of stress on the generator shafts and gears, since the blades absorb the wind torque peaks during the changes of the generator speed of rotation.

The disadvantage of variable-speed operation is that a power conditioner must be employed to play the role of the generator apparent load. However, the evolution of power electronics helps reduce the power-converter cost and increases its reliability, while the higher cost is balanced by the energy production gain.

The torque curves of the generator, consisting of the interconnected wind-turbine/generator system, for various generator output voltage levels under various wind speeds, are shown in Fig. 5. The generator is designed such that it operates in the approximately linear region corresponding to the straight portion of the generator torque curves in Fig. 5, under any wind-speed condition.

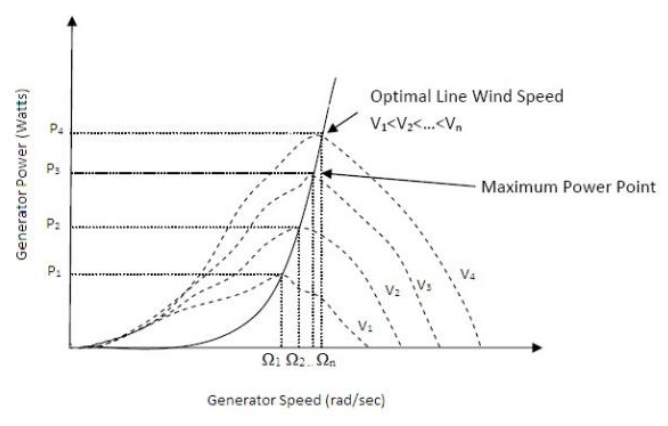

Fig. 4 Generator power curves at various wind speeds.

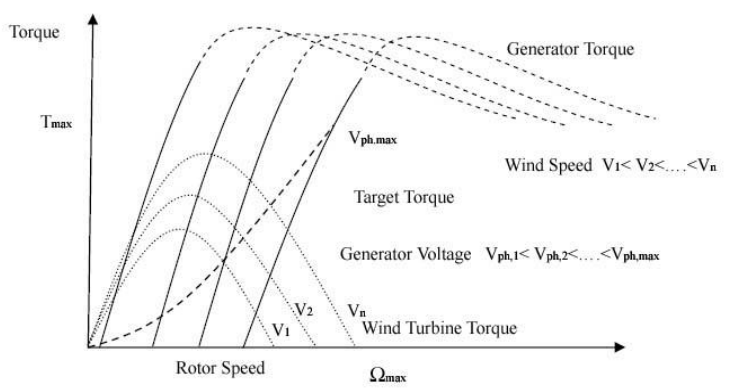

Fig. 5 Torque-speed characteristics of the wind turbine and the generator.

The intersection of the generator torque curve with the wind-turbine torque curve determines the generator operating point. During the MPPT process, a change of the generator apparent load results in variable generator output voltage level; thus, the generator torque is adjusted such that the generator operates at the target torque (e.g., point A) under any wind speed. The target torque line corresponds to the optimal-power-production line indicated in Fig. 4, where the energy is extracted from the generator system is maximized.

\subsection{Problems in the Conventional Methods}

Commonly used WECS topology based on the generator optimal power versus the rotating-speed characteristic, which is usually stored in a microcontroller memory was proposed in many conventional methods. The generator rotating speed is measured; then, the optimal output power is calculated and compared to the actual generator output power. The resulting error is used to control a power interface. Reference [8] used the generator optimal power versus rotor-speed characteristic to derive the target rotor speed for optimal power generation. The target rotor speed is compared to the actual speed, and the error is used to control a dc/dc power converter. The rotor speed is calculated according to the measured GENERATOR output voltage, while the optimal output current is calculated using an approximation of the current versus the rotational-speed optimal characteristic [10] and [16]. The error resulting from 
the comparison of the calculated and the actual current is used to control a dc/dc converter.

The disadvantage of all above methods is that they are based on the knowledge of the generator optimal power characteristic, which is usually not available with a high degree of accuracy and also changes with rotor aging. Apart from this, an accurate anemometer is required for the implementation of the aforementioned methods, which increases the system cost. Furthermore, due to wind gusts of low-energy profile, extra processing of wind-speed measurement must be incorporated in the control system for a reliable computation of the available wind energy, which increases the control system complexity.

To solve the above mentioned limitations, the proposed method is designed with enhanced MPPT technique. It is based on adjusting the boost converter duty cycle. The results of the conventional MPPT technique is compared with enhanced MPPT technique in terms of the conversion efficiency. Thus, the problem of maximizing the output power using the converter duty cycle as a control variable can be effectively solved using this proposed method.

\section{MPPT ALGORITHM}

The MPPT technique used in this project is based on boost converter duty cycle and the generator output power measurements. Although the wind speed varies highly with time, the power absorbed by the generator varies relatively slowly, because of the slow dynamic response of the interconnected wind-turbine/generator system. Thus the duty cycle is used as a control variable to maximize the generator output according to the control law:

$$
D_{m}=D_{m-1}+C_{1} \cdot \frac{\Delta P_{m-1}}{\Delta D_{m-1}}
$$

Where $D_{m}$ is the duty-cycle values at iterations $m, D_{m-1}$ is the duty-cycle values at iterations

$m-1,(0<D m<1) ; \frac{\Delta P_{m-1}}{\Delta D_{m-1}}$ is the generator power gradient at step $m-1$; and $C_{1}$ is the step change.

In order to reduce the impact of the sensor accuracy on the generated power, the control law stated in equation (5) has been implemented based on incremental generator power measurements, rather than absolute measurements, as follows:

$$
\begin{aligned}
& D_{m}=D_{m-1}+\Delta D_{m-1} \\
& \Delta D_{m-1}=C_{2} \cdot \operatorname{sign}\left(\Delta D_{m-2}\right) . \operatorname{sign}\left(P_{i n, m-1}-\right. \\
& \left.P_{i n, m-2}\right)
\end{aligned}
$$

where $\Delta D_{m-1}$ is the duty-cycle change at step $m-1$, $P_{i n, m-1}$ is the converter input-power level at step $m-1$, $P_{\text {in }, m-2}$ is the converter input-power level at step $m-2, C_{2}$ is a constant determining the speed and accuracy of the convergence to the MPP; and the function $\operatorname{sign}(a)$ is defined as

$$
\begin{aligned}
& \operatorname{sign}(a)=1, \quad \text { if } a \geq 0 \\
& \operatorname{sign}(a)=-1, \quad \text { if } a<0
\end{aligned}
$$

\subsection{Proposed MPPT Technique using ANN}

A neural network is an artificial representation of the human body that tries to simulate its learning process. In other words, ANN is an adaptive system that changes its structure based on external or internal information that flows through the network. However, the advantage of using ANN here is to increase the tracking efficiency of the WCES. To do so an ANN has been developed using MATLAB and trained using input dc voltage and dc current. The developed ANN aims to predict the optimum duty cycle by using Equation (9).

In this project, a feed forward neural network is used to train the input samples. This network consists of three layers called an input, an output and one hidden layer. The input and output layer consists of one neuron. The hidden layer consists of ten neurons. The weight which is multiplied with input value and added together to produce a combined value as the input to the output layer. Initially the weights are chosen in such a way that to avoid symmetry problem. This situation happens when all the weights are same then the propagated errors will be the same. Therefore, the initial weights are selected as small values so that the unit activations closest to 0.5 . The corresponding point of maximal weight change occurs thereof.

\subsection{Block Diagram of proposed ANN MPPT}

Fig. 6 shows the proposed WECS with ANN MPPT, which is consisted of a wind turbine, boost converter, controller, and load. A feedback propagation artificial neural network based controller is used to predict the optimum power of the WECS in order to ensure the maximum power operation. The proposed method uses dc-link voltage and duty cycle as control variables for the MPPT. The steps involved in the proposed technique is depicted in Fig. 7 using the flowchart.

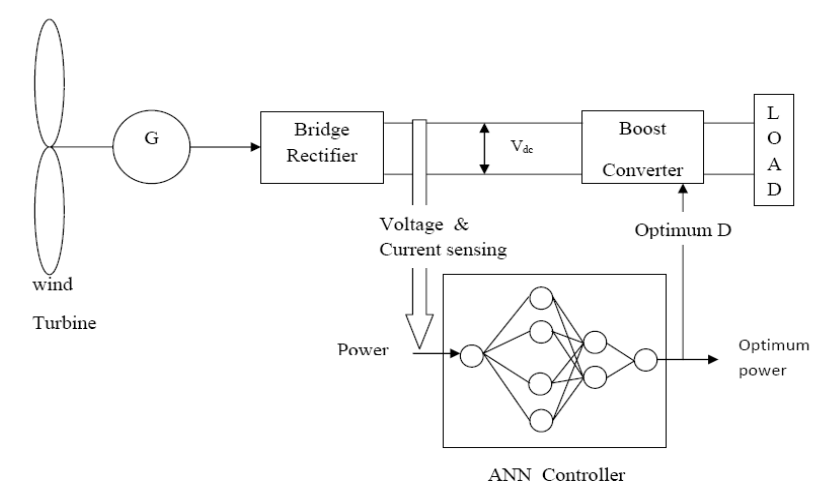

Fig. 6 Block diagram of the proposed ANN MPPT 


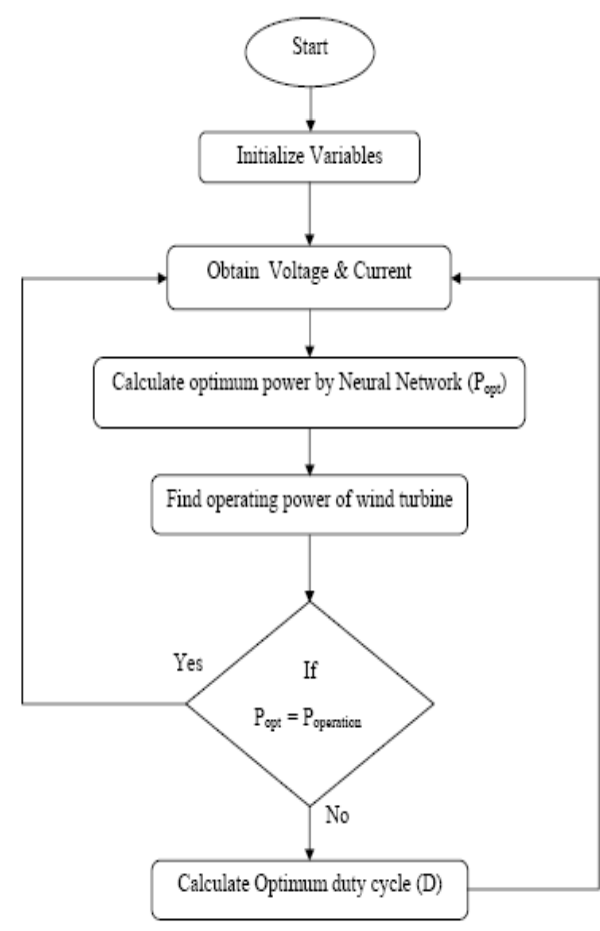

Fig. 7 Flowchart of proposed ANN MPPT

By using the dc-link voltage and dc current, power is calculated and it is given as a input for the proposed ANN and the ouput is in terms of duty cycle according to equations derived previously. Then the output of the ANN is used to switch the boost converter.

\section{RESULTS AND DISCUSSION}

In order to compare the accuracy and power of the WECS, two MPPT algorithms used in this article. The two methods are conventional P\& $\mathrm{O}$ and enhanced MPPT with ANN. Matlab/Simulink is used to implement the tasks of modeling and simulation. Fig. 8 shows the output power of the conventional MPPT method. The output power of the ANN MPPT method is shown in Fig.9.

Power (w)

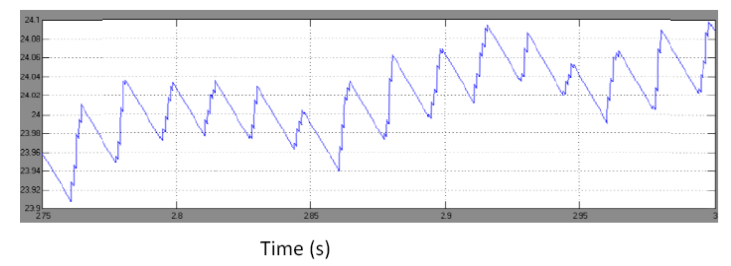

Fig. 8 Output power of conventional MPPT method

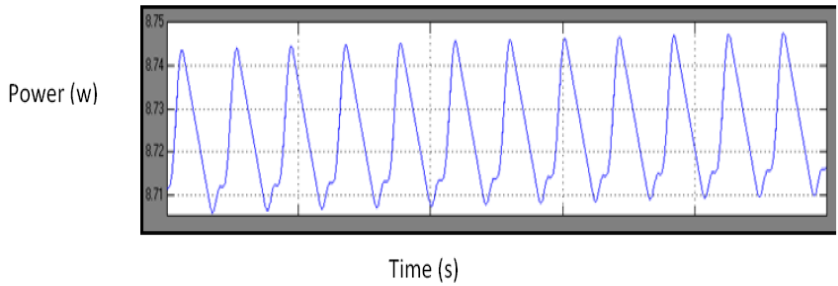

Fig. 9 Output power of proposed ANN MPPT method
To compare the two MPPT methods, the output power at the various wind speed conditions are noted. The performance of the algorithm is showed by having the comparison of output power of the WECS without MPPT and with MPPT methods separately. Fig. 10 shows the comparison of output power without MPPT and with conventional MPPT. Comparison of output power without MPPT and with proposed ANN MPPT. From Fig. 10 \& 11, it is clearly observed that the powers with MPPT algorithms are obviously greater than those without MPPT methods. Therefore the MPPT techniques are really working positively. It is clearly showed with the use of comparison of output powers of the both techniques

The significance of the proposed enhanced MPPT technique can be showed by using Fig. 12 which having the comparison of output power of the conventional MPPT and proposed ANN MPPT technique. From this Fig. 12, it can be concluded that the power produced using the conventional MPPT technique is lower than the power produced using the proposed MPPT technique.

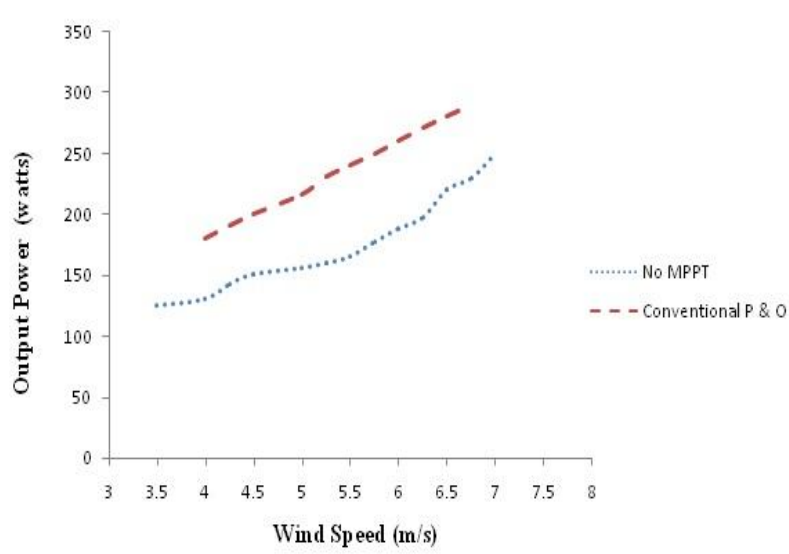

Fig. 10 Comparison of output power of without MPPT \& with conventional MPPT

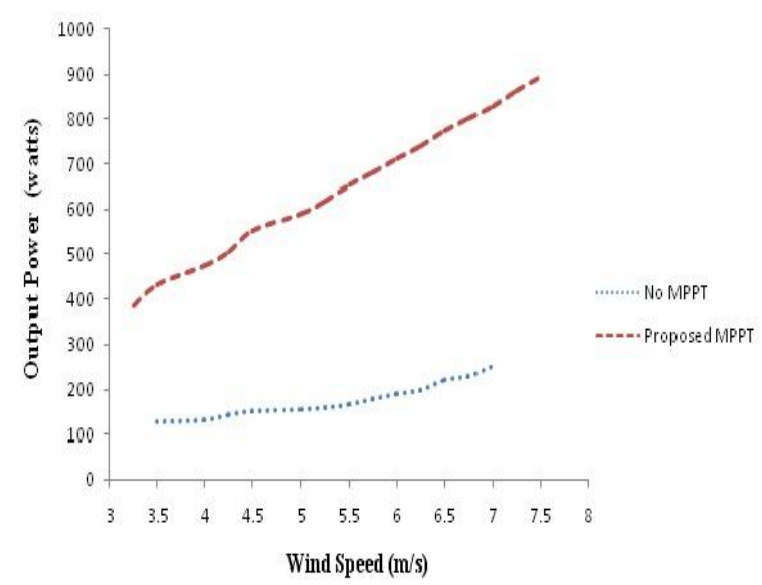

Fig. 11 Comparison of output power of without MPPT \& with proposed MPPT method 


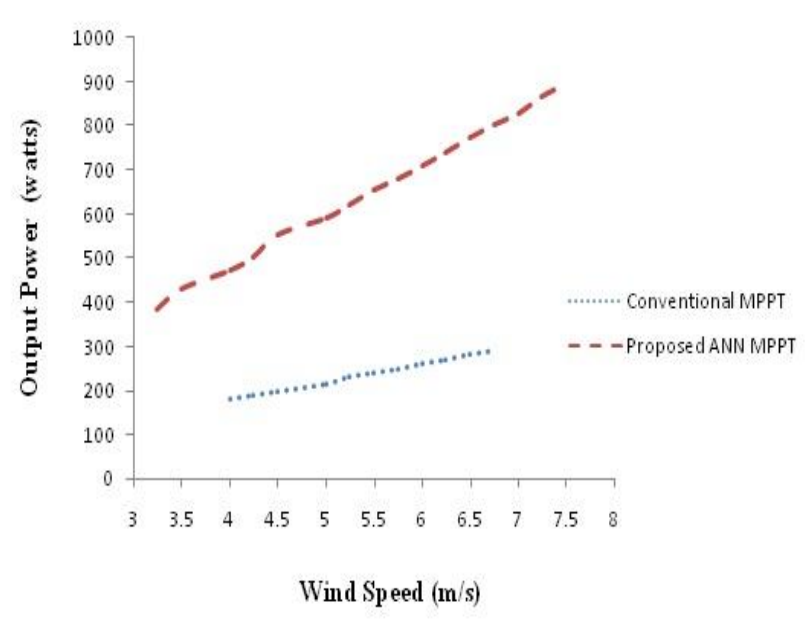

Fig. 12 Comparison of output power of conventional MPPT $\&$ with proposed MPPT method

\subsection{Efficiency Comparison}

To investigate the performance of the proposed WECS further, the efficiency of the conventional and proposed methods are compared. The efficiency is calculated by taking the output of the bridge rectifier and output of the boost converter. The bridge rectifier output is the input and boost converter output is the output for the efficiency calculation. It can be given as

$$
\eta=\mathrm{P}_{\mathrm{i}} / \mathrm{P}_{\mathrm{o}}
$$

Where $\eta$ is the efficiency of the WECS, $\mathrm{P}_{\mathrm{i}}$ is the bridge rectifier $\mathrm{dc}$ power and $\mathrm{P}_{\mathrm{o}}$ is the boost converter output power.

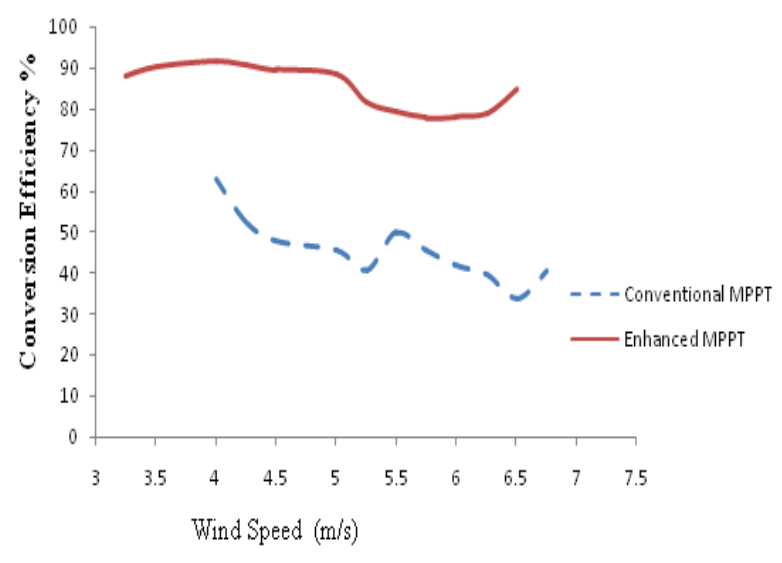

Fig. 13 Comparison of efficiency of conventional MPPT \& proposed MPPT method

To evaluate the performance of the WECS, a set of wind speed is taken to plot the comparison of efficiency for the conventional and proposed MPPT techniques. According to Fig. 13, the conversion efficiency of the proposed MPPT is greater when compared to the conventional MPPT technique. And also it is noted that the efficiency of the proposed method is not less than $77 \%$ whereas the efficiency of the conventional MPPT goes upto $41 \%$.
According to the results, finally the proposed MPPT is having better performance than the conventional MPPT.

\section{CONCLUSIONS}

An enhanced MPPT technique using ANN has been proposed in this thesis. The proposed MPPT technique uses power as input variable which is taken from the dc link voltage and dc current. It uses the dc-link voltage and duty cycle as control input for the MPPT. This in turn will reduce system cost and increase reliability by removing the need for shaft speed sensing. Wind speed measurements are not needed for $\mathrm{P} \& \mathrm{O}$ algorithms. Prior knowledge of the system parameters is not needed for the algorithm to work, making this method more reliable and less complex. Based on the wind speed conditions, the performance of the proposed MPPT is compared with the conventional MPPT. The performance is evaluated by using the output power and efficiency of the above mentioned methods. In both cases, the proposed MPPT technique is better than the conventional MPPT technique.

The proposed method can be easily extended to additional Renewable Energy Sources (RES) control and it can also be modified to control a dc/ac inverter in the case of a gridconnected system. Additional custom power devices can be used to provide the quality power without any power quality issues.

\section{REFERENCES}

[1] R. Datta and V. T. Ranganathan, "A method of tracking the peak power points for a variable speed wind energy conversion system," IEEE Trans. Energy Convers., vol. 18, no. 1, pp. 163-168, Mar. 2003.

[2] J.S. Thongam, P. Bouchard, R. Beguenane, I. Fofana, "Neural network based wind speed sensorless MPPT controller for variable speed wind energy conversion systems", Electric Power and Energy Conference, pp. 1-6, 2010.

[3] Karakaya, A \& Karkas, E, 2013, 'Implementation of neural network-based maximum power tracking control for wind turbine generators', Turkish Journal of Electrical Engineering \& Computer Sciences, vol. 2, no. 1, pp. 1-13.

[4] K. E. Johnson, L. Y. Pao, M. J. Balas, and L. J. Fingersh, "Control of variable- speed wind turbines: Standard and adaptive techniques for maximizing energy capture," IEEE Control Syst., vol. 26, no. 3, pp. 70-81, Jun. 2006.

[5] E. Koutroulis and K. Kalaitzakis, "Design of a maximum power tracking system for wind-energyconversion applications," IEEE Trans.Ind. Electron., vol. 53, no. 2, pp. 486-494, Apr. 2006.

[6] C. Y. Lee, Y. X. Shen, J.-C. Cheng, C. W. Chang, and Y. Y. Li ", "Optimization method basedMPPT for wind power generators," in Proc.World Acad. Sci., Eng. Technol., 2009, pp. 169-172.

[7] S.Morimoto, H. Nakayama,M. Sanada, andY. Takeda, "Sensorless output maximization control for 
variable-speed wind generation system using IPMSG," IEEE Trans. Ind. Appl., vol. 41, no. 1, pp. 60-67, Jan./Feb. 2005.

[8] A.M. De Broe, S. Drouilhet, and V. Gevorgian, “A peak power tracker for small wind turbines in battery charging applications," IEEE Trans. Energy Convers., vol. 14, no. 4, pp. 1630-1635, Dec. 1999.

[9] K. Amei, Y. Takayasu, T. Ohji, andM. Sakui, "A maximum power control of wind generator system using a permanent magnet synchronous generator and a boost chopper circuit," in Proc. Power Convers. Conf. (PCC Osaka 2002), vol. 3, pp. 14471452.

[10] O. Honorati, G. Lo Bianco, F. Mezzetti, and L. Solero, "Power electronic interface for combined wind/PV isolated generating systems," in Proc. Eur. Union Wind Energy Conf., Göteborg, Sweden, 1996, pp. 321-324.

[11] M. Chinchilla, S. Arnaltes, and J. C. Burgos, "Control of permanentmagnet generators applied to variable-speed wind-energy systems connected to the grid," IEEE Trans. Energy Convers., vol. 21, no. 1, pp. 130-135, Mar. 2006.

[12] S. Baike, B. Mwinyiwiwa, Z. Yongzheng, and O. Boon-Teck, "Sensorless maximum power point tracking of wind by DFIG using rotor position phase lock loop (PLL)," IEEE Trans. Power Electron., vol. 24, no. 4, pp. 942-951, Apr. 2009.

[13] P. Ching-Tsai and J. Yu-Ling, "A novel sensorless MPPT controller for a high-efficiency microscale wind power generation system," IEEE Trans. Energy Convers., vol. 25, no. 1, pp. 207-216, Mar. 2010.

[14] K. Tan and S. Islam, "Optimum control strategies in energy conversion of PMSG wind turbine system without mechanical sensors," IEEE Trans. Energy Convers., vol. 19, no. 2, pp. 392-399, Jun. 2004.

[15] W. Quincy and C. Liuchen, "An intelligent maximum power extraction algorithm for inverterbased variable speed wind turbine systems," IEEE Trans. Power Electron., vol. 19, no. 5, pp. 12421249, Sep. 2004.

[16] G. Lo Bianco, O. Honorati, and F. Mezzetti, "Smallsize stand alone wind energy conversion system for battery-charging," in Proc. 31st Universities Power Engineering Conf., Iráklion, Greece, 1996, pp. 6265.

[17] M. G. Simoes, B.K. Bose, and R. J. Spiegel, "Fuzzy logic based intelligent control of a variable speed cage machine wind generation system," IEEE Trans. Power Electron., vol. 12, no. 1, pp. 87-95, Jan. 1997.

[18] M. G. Simoes and B. K. Bose, "Design and performance evaluation of fuzzy-logic-based variable-speed wind generation system," IEEE Trans. Ind. Appl., vol. 33, no. 4, pp. 956-965, Jul./Aug. 1997.

\section{BIOGRAPHIES}

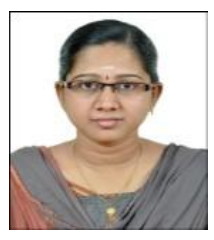

Monica.S received the B.E. degree in Electrical and Electronics Engineering from Velalar College of Engineering \& Technology, Tamil Nadu, India in 2006. She is currently working toward the M.E. degree in Power Systems Engineering in Vivekanandha College of Engineering for Women, Elayampalayam under Anna University Chennai, Tamil $\mathrm{Nadu}$, India. She is a IEEE student member. Her interests include Renewable energy power generation, wind energy conversion systems, and Power quality improvements.

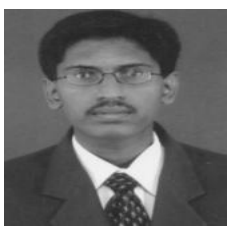

Ramesh.K received his B.E. degree in Electrical and Electronics Engineering from K.S.R.College of Technology, Tamilnadu, India in 2002 and M.E. in Applied Electronics from Kongu Engineering College, Anna University, Chennai in 2005 and also received the M.B.A. in Systems from PRIDE, Salem, India in 2005. At present, he is working as an Assistant Professor in Vivekanandha College of Engineering for Women, Elayampalayam (Tamilnadu), India. Presently he is a Part time (External) Research Scholar in the Department of Information and Communication at Anna University, Chennai (India). He is life member of ISTE, member in IEEE, member in International Association of Engineers (IAENG) and member in International Association of Computer Science and Information Technology (IACSIT). His fields of interest include Model order reduction, Controller design and Optimization Techniques.

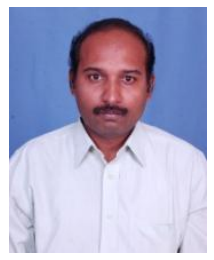

Prakash.R received his B.E. degree from Government College of Technology, affiliated to Bharathiyar University, Coimbatore, Tamilnadu, India in 2000 and completed his M.Tech. degree from the College of Engineering, Thiruvanandapuram, Kerala, India, in 2003. He obtained his Ph.D. degree in Electrical and Electronics Engineering from Anna University, Chennai, India, in 2012. At present he is working as Professor and Head in Department of Electrical and Electronics Engineering, Vivekanandha College of Engineering for Women,Tiruchengode, Tamilnadu, India. His research interests include Adaptive Control, Fuzzy Logic and Neural Network applications to Control Systems. 